\title{
DESIGN E MUSICOTERAPIA: aproximações em um processo participativo
}

\author{
Natalia Chaves Bruno \\ Mestranda em Design PUC-Rio \\ nataliacbruno@gmail.com
}

\begin{abstract}
Resumo: O presente artigo tem por objetivo apresentar a união do design e a musicoterapia no processo de desenvolvimento de um produto como projeto de conclusão do curso de Design na PUC-Rio, resultado da parceria entre a pesquisadora e a musicoterapeuta Ana Sheila Tangarife no IPCEP(Instituto de Psicologia Clínica, Educacional e Profissional). No artigo é apresentado o caminho percorrido que permitiu unir essas duas áreas do conhecimento a fim de gerar, a partir desse encontro, um objeto que valorizasse o contexto musicoterápico assim como as pessoas ali envolvidas. Os objetos desenvolvidos, vestimentas musicais interativas, não estavam pré-definidos antes dos encontros, mas foram formados a partir da vivência nas sessões de musicoterapia. Segundo relatos da musicoterapeuta, o processo e as vestes trouxeram desenvolvimento na área musical, motora e vocal para os pacientes.
\end{abstract}

Palavras-chave: design participativo, design de interação, musicoterapia, vestimentas, deficiência intelectual

\section{INTRODUÇÃO}

O curso de Design da PUC-Rio, desde os anos 80, propõe aos seus alunos o desenvolvimento de projetos a partir da vivência com grupos sociais reais, desta forma, a situação hipotética é trocada por uma real e o aluno passa a projetar levando em consideração as singularidades e especificidades do grupo identificadas a partir da convivência. Esse processo é chamado desde então de Design Social, que define-se por priorizar a lógica do usuário ao invés da lógica da produção (DIAS e CORTES,2007).

O método escolhido para o desenvolvimento deste projeto foi o método participativo (COUTO, Rita 1989) que tem por essência o trabalho realizado em parceria com um grupo social, aonde a pessoa que conduz a atividade terá participação essencial em todas as etapas do processo. O projeto não é feito para o profissional, mas com ele. O profissional (interlocutor) escolhido para a realização deste trabalho foi a musicoterapeuta Ana Sheila Tangarife, que trabalha com um grupo de deficientes intelectuais no IPCEP, Instituto de Psicologia Clínica Educacional e Profissional.

"O objeto gerado sem a presença do interlocutor e sem o desenvolvimento do afeto como formador do coletivo tem uma participação aleatória e indiferente nos coletivos que dele lançam mão, sendo apenas um fenômeno de consumo nestas comunidades. Enquanto que o objeto desenvolvido 
com a participação ativa do interlocutor e com a presença desse afeto na comunidade envolvida transforma esta última num coletivo sujeito, participando de modo significativo e fundamental dos acontecimentos desta comunidade". (in Pacheco,1996)

\section{DESENVOLVIMENTO}

No presente trabalho serão apresentadas as etapas percorridas no processo fazendo uso das ferramentas características do método adotado. As vivências aqui expostas tecem a relação entre as duas áreas de conhecimento, que ao final do percurso, toma forma de um instrumento de vestir cuja proposta é o acolhimento, a interatividade e o estímulo às movimentações corporais do grupo durante as sessões de musicoterapia.

\subsection{Observações}

A primeira etapa para o desenvolvimento de um projeto com base no método participativo, consiste na observação participante, que tem base na pesquisa antropológica. Neste momento as atividades da musicoterapeuta são acompanhadas a fim de compreender o seu universo e observar a sua dinâmica de trabalho. Os registros dos encontros são feitos a partir de anotações das palavras ditas por ela e a criação de desenhos das situações observadas. A observação foi realizada no IPCEP e nas aulas de Licenciatura em Música no Conservatório Brasileiro de Música (CBM).

As sessões de musicoterapia iniciam-se com a profissional sugerindo aos pacientes a ida até o armário para a escolha de um instrumento musical para ser utilizado por cada um. Uma vez reunidos na sala, a musicoterapeuta começa estimulando o grupo a dizer como se sentem e como passaram o dia, após essa conversa inicial, a parte musical é introduzida a partir das sugestões de músicas pedidas pelos pacientes e tocadas ao piano pela terapeuta. Os pacientes sugerem com frequência as mesmas musicas, no entanto, a terapeuta ao longo da sessão busca instiga-los a lembrarem de novas canções. A sessão de aproximadamente quarenta e cinco minutos é dividida entre momentos livres de trocas musicais e dinâmicas que trabalham elementos característicos da música, como ritmo, intensidade e tempo.

Nesta etapa o pesquisador se posiciona na roda juntamente com o grupo e interfere o mínimo possível na atividade, manifestando-se somente quando a musicoterapeuta ou um dos pacientes solicita.

Durante a observação realizada no CBM o pesquisador registra as informações passadas pela musicoterapeuta que conduz a aula de forma descontraída e natural. Durante a aula, a musicoterapeuta propicia um espaço de tempo para que os alunos relatem suas experiências, em seus diversos estágios, acompanhados por conselhos e conteúdos específicos ministrados pela musicoterapeuta. Percebe-se em suas falas para o grupo de alunos do CBM o objetivo de valorizar a profissão ali ensinada:

"Na música vocês vão ser os salva vidas dessas crianças, vocês vão integrá-las." "a minha alma acredita nisso com toda a força" "não existe aprendizagem sem afeto, como já dizia Piaget".

\subsection{Identificação do tema}

Durante os quatro encontros realizados nos ambientes de trabalho da musicoterapeuta, palavras que compõe o seu universo vocabular foram recolhidas através das anotações no diário de campo, com o objetivo de desenvolver, junto com a profissional, a dinâmica chamada "jogo de palavras".

Para a realização do jogo, as palavras recolhidas são devolvidas para a 
musicoterapeuta em forma de cartões e é solicitado que esta os arrume da forma que desejar. Após um longo período lendo cada palavra, a musicoterapeuta relatou que iria dividi-las em grupos de pensamentos. Ao final da arrumação explicou seu raciocínio formando frases com as colunas que tinha construído.

-"o grupo de musicoterapia trabalha criando saúde, vida, aqui no hoje e agora, brincando e tocando com a música"

-"o corpo, o canto, a fala com prazer trazem uma comunicação pelo instrumento que é uma extensão do aluno"

-"Ideal é não ter preconceitos, rótulos. Não perguntar idade mental e sim acolher."

Ao falar essa frase a musicoterapeuta explicou que direciona seu olhar para enxergar o ser humano e não seus rótulos e dificuldades. A musicoterapeuta busca conhecer primeiramente o paciente e seus gostos antes de conversar com os pais ou ver o seu diagnóstico.

- "O desacerto, a surpresa nos fazem voltar a começar; nascer de novo" Nesta frase, explicou que o desacerto é de grande importẩncia para a musicoterapia, pois o processo é muito lento e por trabalhar com a mente e a emoção humana, os "erros" se tornam comuns, sendo necessário transformá-los em agentes de mudanças para o grupo.

-"A deficiência intelectual sensorial que traz a mesmice provoca uma rejeição, exige que a gente se interesse já, a levar possibilidades de inclusão"

-"Alma, afeto e força são portas para uma visão do ser humano"

Duas frases foram destacadas pela musicoterapeuta: humano"

"alma, afeto e força são portas para uma visão do ser

"o grupo de musicoterapia trabalha criando saúde, vida, aqui no hoje e agora, brincando e tocando com a música".

As frases estão relacionadas às suas crenças e a valorização do ser humano através do afeto que gera mudanças, e a forma como o trabalho da musicoterapia é desenvolvido, respectivamente.

Após o desenvolvimento de outras frases e uma nova sessão de escolha, a musicoterapeuta, a partir da combinação de três sentenças, deu origem a frase-tema do projeto: "Acolhendo a música do ser humano, o corpo cria vida para nascer de novo." Segundo relatos da musicoterapeuta essa frase foi escolhida, pois valoriza receber ("acolher") os pacientes da forma como estão e a necessidade de trazer o novo, de estimular o corpo e a vida de cada um ali presente.

\subsection{Experimentação- geração de conceito}

A etapa de experimentação e geração de conceitos tem como base a frase-tema desenvolvida anteriormente. Neste momento o pesquisador desenvolve duas séries de experimentos/ objetos de intervenção: objetos simples com propostas diferenciadas de usos que tenham relação com a frase. O objetivo desta etapa é identificar quais situações são mais valorizadas pela musicoterapeuta durante seu trabalho com os pacientes do IPCEP.

A seguir são apresentadas as duas séries de experimentos realizados, indicando a intenção de uso para alguns, como forma de exemplo. 


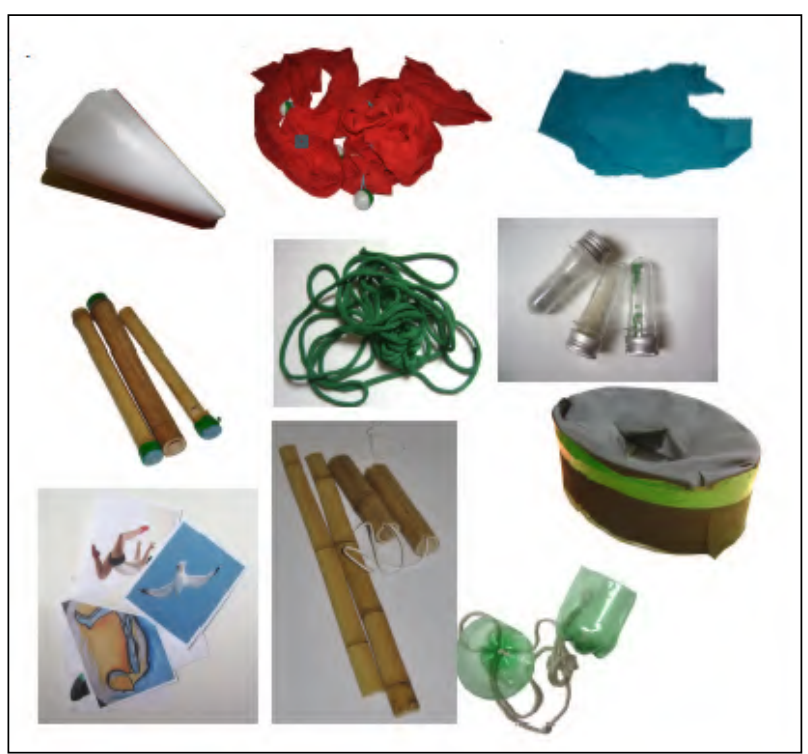

Figura 1 - Série Um experimentação

Fonte: Elaborado pelo autor, com base na pesquisa realizada

\begin{tabular}{|l|l|}
\hline Experimentos/objetos de intervenção & objetivos \\
\hline Megafone de cartolina & Estimular a voz \\
\hline Tecido chocalho & Estimular dança \\
\hline Tecido do acolher & Receber o movimento \\
\hline Cazus & Estimular a voz \\
\hline Cordão & Estimular contato com os outros pacientes \\
\hline Chocalhos em tubos & Estimular sons com outros instrumentos \\
\hline Imagens de corpo e liberdade & Estimular movimento \\
\hline Bambu com elástico & Descoberta corporal \\
\hline Caixa surpresa & Ideias para repertório \\
\hline
\end{tabular}

Quadro 1 - Série um experimentação

Fonte: Elaborado pelo autor, com base na pesquisa realizada.

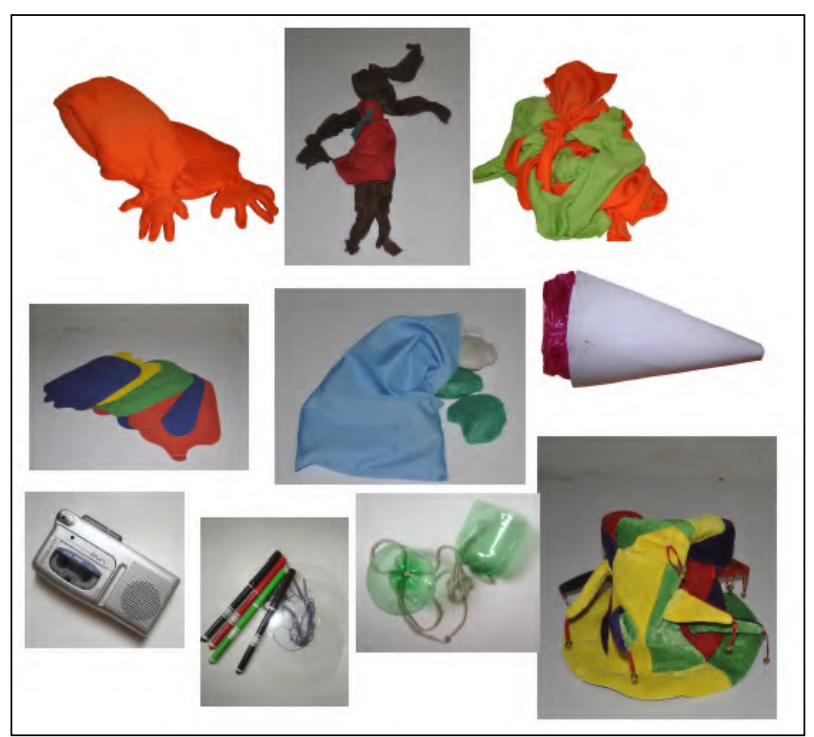

Figura 2 - Série Dois experimentação

Fonte: Elaborado pelo autor, com base na pesquisa realizada

\begin{tabular}{|l|ll|}
\hline Experimentos/objetos de intervenção & objetivos \\
\hline Abraço laranja & Gerar abraços em dupla & \\
\hline Boneca do acolher & Estimular aproximações/histórias com a \\
\hline
\end{tabular}




\begin{tabular}{|l|l|}
\hline Saco sensorial & boneca \\
\hline Cone iluminado & Despertar os sentidos \\
\hline Gravador & Gerar surpresa com as mudanças de cores \\
\hline CDs e canetas permanentes & $\begin{array}{l}\text { Gravar manifestações do } \\
\text { ambiente }\end{array}$ \\
\hline Telefone sem fio & Escrever músicas no CD \\
\hline Chapéu colorido com guizos & Estimular manifestações vocais \\
\hline
\end{tabular}

Quadro 1 - Série um experimentação

Fonte: Elaborado pelo autor, com base na pesquisa realizada.

Durante a fase de experimentação, o pesquisador coloca o material no chão e não explicita as intenções da criação de cada objeto para não direcionar o uso dos mesmos. A musicoterapeuta solicitou que os pacientes pegassem os objetos deixando-os livres para escolherem. No primeiro dia desta etapa observou-se o estranhamento dos pacientes refletido no receio de pegar algum material, no entanto, a musicoterapeuta, a partir de frases encorajadoras, estimulou a ação dos pacientes.

Constatou-se a recorrência do uso do material como links para dar ideias de músicas a serem tocadas pela musicoterapeuta, fazendo uma mediação do significado ao atribuir um significado que vai além do objeto em si (TANGẢRIFE, 2012). Para exemplificar essa relação de link, é apresentado um trecho do diário de Campo

"Uma das pacientes escolheu o véu azul, colocando-o sobre o corpo e a musicoterapeuta pediu que a turma pensasse em uma música que parecesse com o véu. A diz que o véu é 'coisa do clone', então a terapeuta comeca a tocar uma música que lembra dança do ventre e a aluna dança girando, rebolando, levantando os braços enquanto os demais alunos experimentam os outros instrumentos. Em um determinado momento $\boldsymbol{B}$ toca no cazu algo semelhante ao barulho do trem e um aluno comenta "olha o trem!", imediatamente a musicoterapeuta improvisa uma música e toca em seguida $O$ trenzinho do caipira. Ao terminar comenta: "olha nós fizemos uma viagem de trem com a $\boldsymbol{B}$ e com a $\boldsymbol{C}$.

Com o objetivo de estimular a manifestação vocal dos pacientes a musicoterapeuta solicita aos mesmos um depoimento sobre o dia e o que acharam dos objetos, ao final do primeiro dia de experimentação.

-"Foi uma coisa diferente, coisa que a gente nunca viu" (participante A e participante D)

- "Canta muita música, e é moderna transmite o som bacana" (participante B falando sobre o cazu)

-"Serve pra cantar e pra imitar o som do trem" (participante C falando sobre o cazu)- "Eu gostei desse, acho bonito" (participante B sobre o chocalho transparente)

-"Eu gostei também, lembra o telefone sem fio" (participante A sobre o bambu com elástico)

- "Eu parecia uma rainha, gostei muito" (E diz que se sentiu uma rainha usando o tecido azul)

-"Eu não gostei muito, ele não toca nada" (F sobre o auto falante de cartolina)

-"Eu gostei de poder vestir e tocar" (B sobre o tecido vermelho) 
$\mathrm{Na}$ segunda série de experimentos, a dinâmica aconteceu de forma similar à anterior: a musicoterapeuta deu continuidade as frases para estimular os pacientes a interagirem com os objetos, trazendo-os para o contexto musical como forma de links.

"A musicoterapeuta pegou a boneca, colocando-a no colo em movimento de ninar, em seguida deixou no piano ao seu lado. Ana Sheila falou para C, a paciente que havia escolhido o chapéu com guizos:"Vamos ver que música combina com esse chapéu", pediu que ela saísse da sala e entrasse fazendo uma dança livre, pois iria improvisar no piano. $\boldsymbol{C}$ veio dançando alegremente e rindo bastante.

Em seguida, foi a vez de $\boldsymbol{B}$ que tinha escolhido o abraço laranja, a musicoterapeuta perguntou que música ela queria para aquele objeto e a paciente relembrou uma música antiga 'menina te carreguei no colo te coloquei para dormir.' A musicoterapeuta improvisou um acompanhamento no piano e comentou o acesso da paciente à uma memória bem antiga.

Observou-se que na segunda série de experimentos os pacientes já estavam familiarizados com a situação e se disponibilizaram mais rapidamente a fazerem a escolha do material para as dinâmicas.

\subsection{Análise da experimentação}

Esta etapa tem por objetivo compreender a visão do parceiro no projeto (musicoterapeuta) em relação ao processo anterior de experimentação, identificando que experimentos/ objetos de intervenção foram mais relevantes e valorizados dentro de seu contexto de trabalho. Esta identificação é realizada a partir de uma dinâmica denominada "quente e frio". Neste procedimento o parceiro organiza o material composto pelas duas séries de objetos em uma linha sendo o primeiro objeto o mais relacionado a frase-tema e seu trabalho, e o último o que está mais distante da proposta.

Durante a dinâmica realizada pela musicoterapeuta, os seguintes objetos foram colocados mais próximos a frase, mostrando a relevância destes dentro do contexto observado.

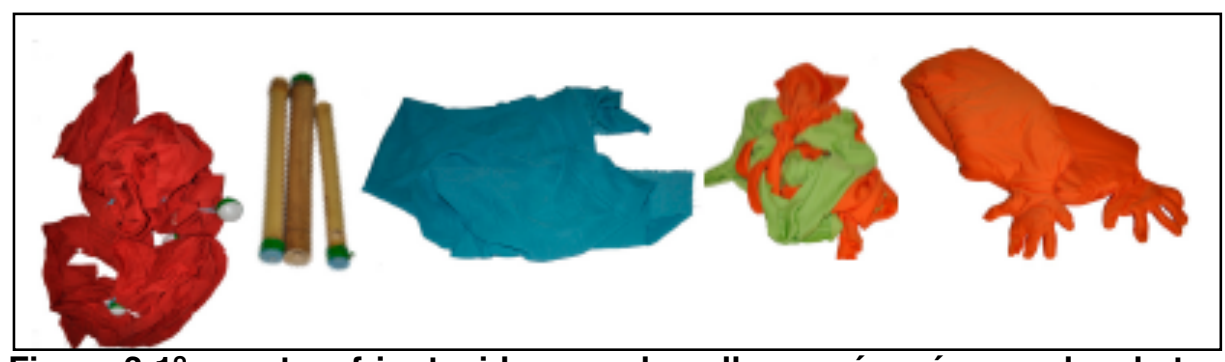

Figura 3-1 ${ }^{\circ}$ quente e frio- tecido com chocalho, cazús, véu, argolas de tecido e o abraço laranja

Fonte: Elaborado pelo autor, com base na pesquisa realizada.

Ao explicar sobre a escolha, a musicoterapeuta reforçou a importância do tecido por ter gerado o movimento corporal nos pacientes e este, associado ao som, se mostrou altamente adequado para a prática da musicoterapia, tendo em vista que o elemento principal das sessões é o som. Unindo a sonoridade ao tecido, o som passa a se relacionar diretamente com 0 movimento, sendo um estímulo para os pacientes.

A partir da dinâmica realizada foi possível compreender que o tecido funciona como o instrumento (suporte) e o barulho/ som produzido vem do corpo através da fala/canto ou do movimento. 
Esse conjunto de informações proporcionou identificar os primeiros requisitos para o projeto, sendo eles:

$\oplus$ através do objeto acolher a movimentação corporal dos pacientes afim de gerar sons

- usar o tecido como suporte para o elemento sonoro, sendo um instrumento

favorecer um som produzido pelo paciente

$\oplus$ permitir usos variados

• ser de fácil uso.

Após a identificação desses primeiros requisitos, iniciou-se uma nova etapa de experimentação focada no objetivo de movimentar o corpo gerando som. O pesquisador realizou uma série de experimentos formando três grupos conceitos:

elemento sonoro escondido- os objetos que geram som são escondidos dentro do suporte de tecido, o objetivo é identificar se o fato do som estar escondido desperta a atenção dos pacientes; movimento em grupo- visando a disposição dos alunos em roda na sala, o objetivo é valorizar o movimento em grupo aproximando-os fisicamente permitindo a visualização do tocar junto; formas simples de veste- considerando o requisito de ter fácil usabilidade, nesse conceito foi explorado as diferentes formas de vestes com o objetivo de entender qual opção seria mais intuitiva e de fácil compreensão.

Nesta etapa foram criados nove experimentos, posteriormente analisados pela musicoterapeuta na segunda dinâmica do "quente e frio".

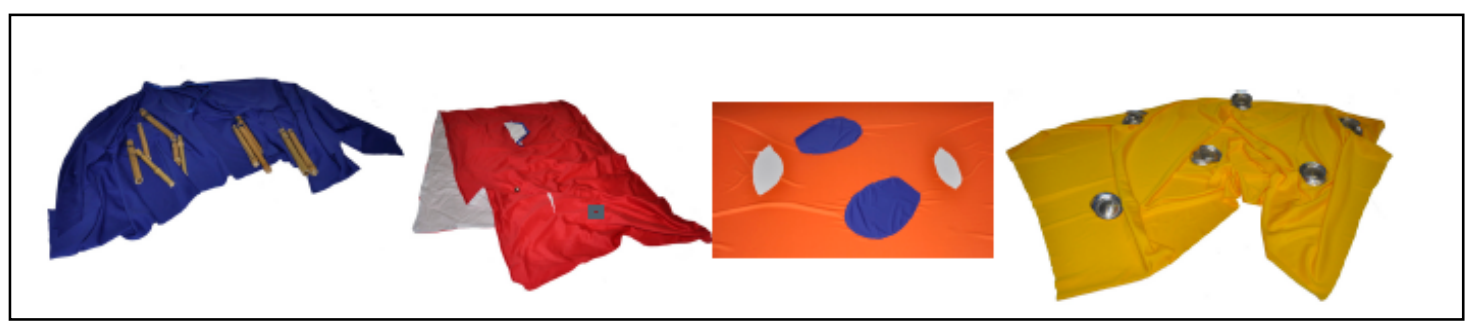

Figura 4 - $2^{\circ}$ quente frio- poncho com cazu, xale de escolhas, dança em dupla, xale com latinhas

Fonte: Elaborado pelo autor, com base na pesquisa realizada.

A musicoterapeuta relatou que o primeiro elemento apresentava uma forma fácil de vestir com a sonoridade do bambu; para o segundo, sublinhou a importância da comunicação visual da música tocada e a possibilidade de escolha musical nos cartões; no terceiro, as cores chamativas foram reforçadas; e no quarto elemento, destacou a relevância do material sonoro estar exposto. requisitos:

A partir da dinâmica realizada foi possível identificar os seguintes

$€$ O produto deverá ter cores chamativas;

$\oplus$ O elemento sonoro deve estar exposto;

- Através do produto comunicar o som produzido pelos alunos.

\subsection{Identificação do produto e desenvolvimento}


Com todos os requisitos definidos, foi possível identificar que o produto a ser desenvolvido seria um conjunto de vestimentas no formato de poncho, com os elementos sonoros expostos e pequenos bolsos internos para cartões com dica musical. Como forma de viabilizar a comunicação do som produzido pelos pacientes, o pesquisador propôs o uso de luzes que fossem ativadas a partir do som ou do movimento. Após alguns testes e conversas com a musicoterapeuta, identificamos que esse estímulo visual seria relevante para o contexto.

Uma vez definido o produto, iniciou-se a etapa de construção dos modelos. Nesse processo a musicoterapeuta esteve a par de cada decisão tomada e também participou na escolha de materiais. Foi sugerido por ela a junção de dois elementos (a conta de aljofre com o disco metálico) para a obtenção de um som mais presente, assim como a variedade no comprimento das vestes para atender ao publico masculino e feminino. Suas considerações foram testadas e adotadas pelo pesquisador.

A seguir apresenta-se o desenho da coleção expondo os materiais utilizados para a sonoridade, bem como as diferentes propostas de interatividade com luzes para cada veste.

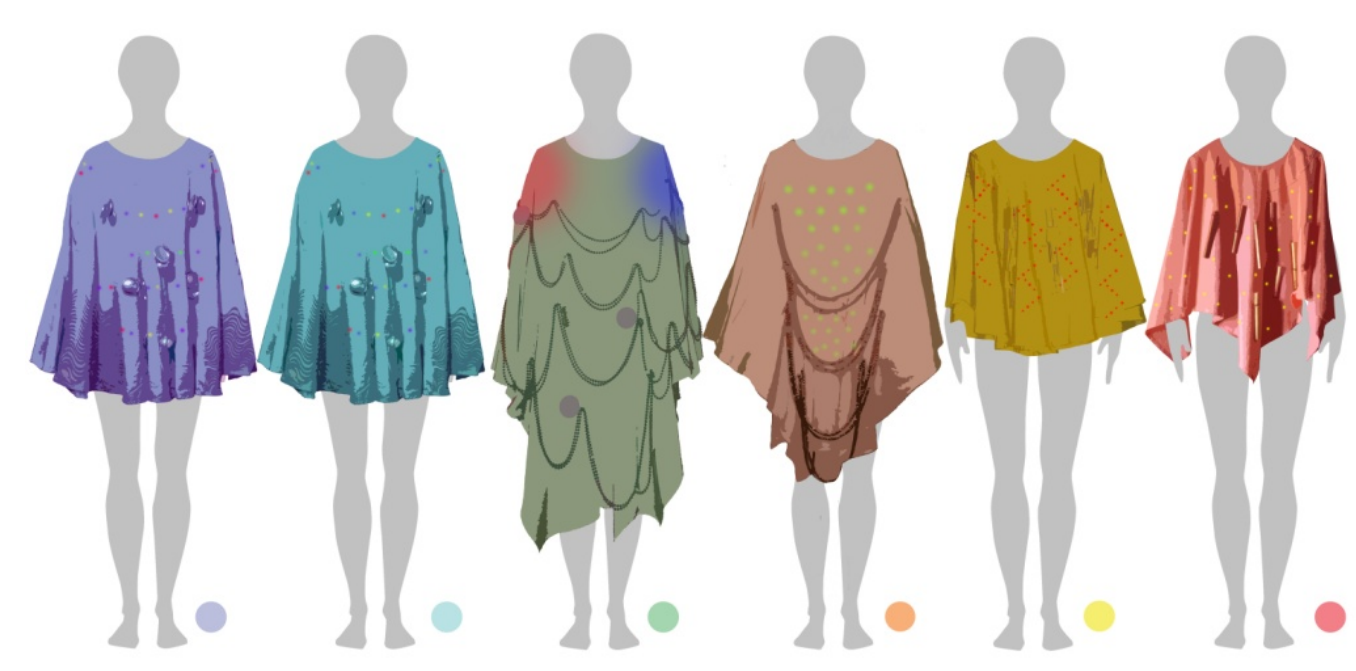

bases de lata de alumínio

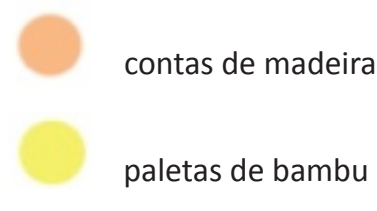

bases de lata de alumínio

paletas de bambu

aljofres e bases de lata de alumínio

tubos de bambu

Figura 5 - Desenho de coleção

Fonte: Elaborado pelo autor, com base na pesquisa realizada.

\section{Conceitos de luz:}

A criação dos conceitos de luz teve como base um vídeo gravado no IPCEP dos pacientes dançando com os experimentos de tecido (mais próximos do produto final) Dessa forma foi possível identificar os movimentos mais presentes e desenhar as luzes para valorizar as características corporais do 
grupo.

Ilhas de luz (movimento do

corpo)

Tendo como pornto de partida um movimento bem frequente do grupo, o balanço do corpo no sentido horizontal, o conceito luz líquida foi desenvolvido. Nesta veste nuvens de luzes acendem alternadamente nas laterais de acordo com a direção (direita/esquerda) do aluno.

Luz em traços (som do chocalho)

Tendo como base o posicionamento vertical dos elementos sonoros e a sonoridade suave produzida pelos mesmos, optou-se pelo desenho da luz em forma de traços alternando a sua intensidade de acordo com o som produzido.

Luz dispersa (contato e som)

Nas vestes lilás e azul a luz acontece a partir do contato entre duas pessoas dançando. No poncho vermelho o led acende a partir do som produzido pelos bambus encostando entre si. Neste conceito a luz pisca de forma mais aleatória.

Luz líquida (movimento do tecido)

O conceito luz liquida teve como referencia a dança de um aluno que utilizou o tecido como um objeto dançante. Desta forma, nesta veste a luz se comporta como um líquido que se move a partir da interação com o tecido.

\subsection{Experimentação Final}

Posteriormente ao desenho da coleção e os conceitos de interatividade, todos as vestes foram produzidas, sendo somente um par (referente ao conceito de luz dispersa e a proposta de dançar junto) desenvolvido com a interatividade das luzes (uso do micro controlador Arduíno-LilyPad). A introdução de um micro controlador foi feita de forma gradativa durante a etapa de identificação do produto e desenvolvimento.

$\mathrm{Na}$ experimentação final todos os ponchos foram levados para o IPCEP. A musicoterapeuta organizou a sala para deixar mais espaço livre e propôs várias danças ao grupo, estimulando-os a pensarem na festa Julina do grupo que estava se aproximando. Logo no início da dança a paciente ' $F$ ' disse que queria colocar o da luz "eu quero o que dança junto, qual é?" e quando a musicoterapeuta abriu o espaço para a escolha das vestes ' $F$ ' foi direto nos ponchos lilás e azul, ao escolher ficar com o lilás, entregou o outro para a amiga 'B'. Os outros pacientes foram escolhendo as vestes aos poucos identificando-as pelas cores. Inicialmente a dança ocorreu de forma livre, em seguida a musicoterapeuta interviu propondo uma roda e depois que cada uma se apresentasse fazendo uma dança. 

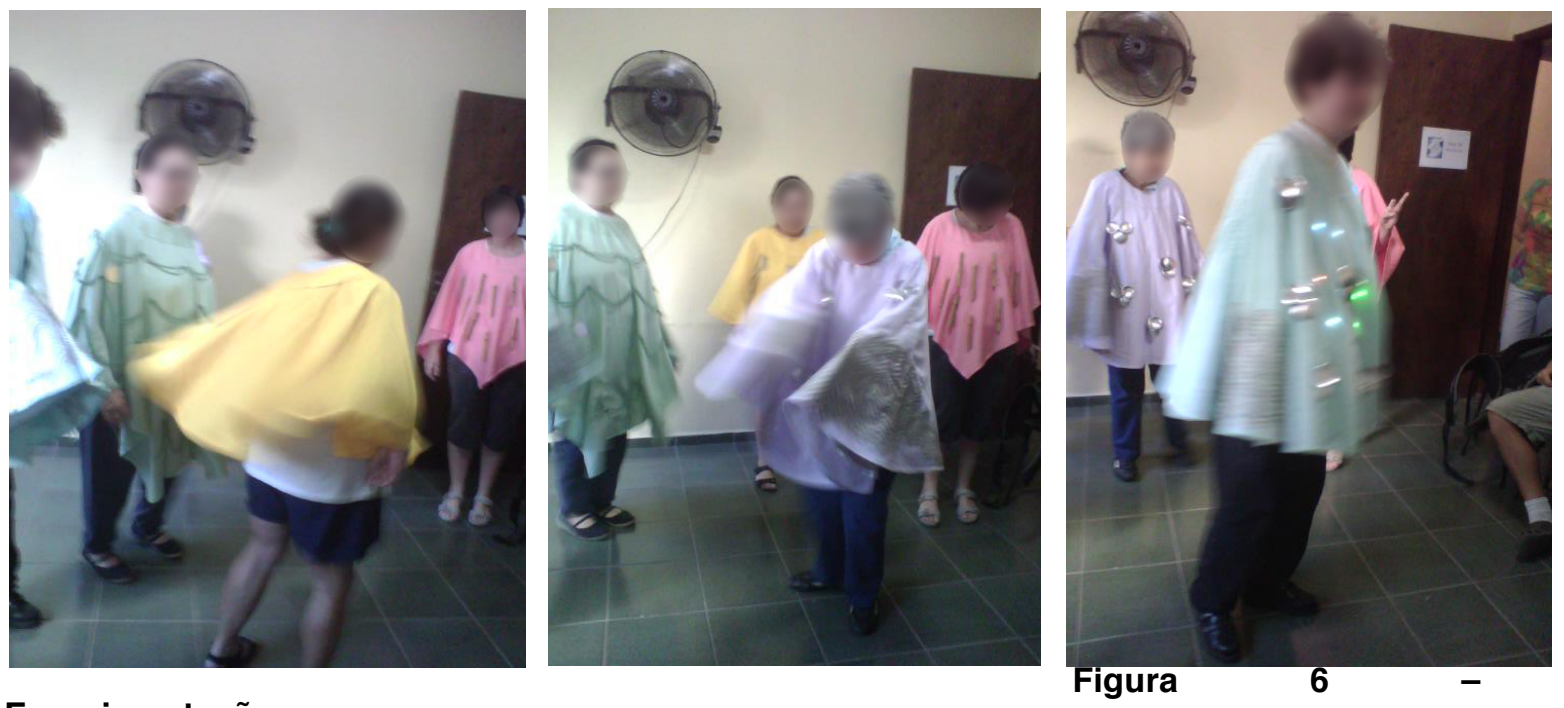

Experimentação

Fonte: Elaborado pelo autor, com base na pesquisa realizada.

\section{CONCLUSÃO}

A criação das vestes musicais dentro do contexto do IPCEP somente apresentou ao mundo em forma tridimensional os movimentos já pré-existentes naquele local, movimentos esses de valorização do ser humano e a crença no desenvolvimento do "capital humano de adaptabilidade" (FEURSTEIN,1989). O produto foi desenvolvido no momento em que o grupo de musicoterapia (musicoterapeuta e seus estagiários) estava propondo uma nova abordagem para os pacientes, apresentando-se abertos para as novidades frutos desse encontro.

A musicoterapeuta em seu relatório da pesquisa no período de desenvolvimento deste projeto, atribuiu avanços na área musical, vocal e corporal dos pacientes ao processo de criação das vestes, sendo constatado pelas manifestações vocais acompanhadas de fluência e coerência e exploração espacial. (TANGARIFE, 2012)

O processo de design participativo potencializou as dinâmicas do local dentro da sessão de musicoterapia, fortalecendo os valores e aspirações da interlocutora. A trajetória que se realiza em conjunto possibilita enxergar as particularidades do contexto e de cada movimento realizado, gerando produtos sustentáveis em seu contexto de desenvolvimento com valor diferenciado e único. Compreendemos que o processo, da forma como foi conduzido, respeitando e acolhendo as manifestações do local, teceu a parceria entre essas duas áreas do conhecimento, apresentando mais uma possibilidade de interdisciplinaridade para designers e musicoterapeutas.

\section{REFERÊNCIAS}

COUTO, Rita. O ensino da disciplina de Projeto Básico sob o enfoque do Design Social. Rio de Janeiro: Departamento de Educação PUC-Rio. 1991. Dissertação (mestrado)

COUTO, Rita Maria ET alii. Desenho Social: por uma metodologia participativa, IV Congresso da Associação Latino-Americana de Desenho Indutrial, Havana, 
Cuba, 1989

DIAS, Carla e CORTES, Carlos André. Design Social ou Design Participativo:uma experiência de ensino. $4^{\circ}$ Congresso Internacional de Pesquisa em Design, 2007 (disponível:http://cursos.faberludens.com.br/file.php/37/Design_Social_ou_Design _pa rticipativo_uma_experi_EAncia_de_85.pdf acesso: 25/7/2012)

FEUERSTEIN, R. and cols. - Don't accept me as I am- helping "retarded" people to excel. New York: Plenum Press, 1989.

PACHECO, Heliana Soneghet. O Design e o Aprendizado:Barraca:quando o design social deságua no desenho coletivo.Rio de Janeiro. Departamento de Artes PUC-Rio. 1996. Dissertação (mestrado)

TANGARIFE, Ana Sheila. Relatório Final de Pesquisa (2010-2012). Rio de Janeiro. 2012 